\title{
Stable Directing System for Cross Layer Dependability for Ultra Large Scale Framework
}

\author{
S.R. Sri Vidhya, C. Geetha, Vimala D
}

\begin{abstract}
Ultra wideband (UWB) radio is ascending as an attracting physical layer for adaptable uncommonly picked structure (MANET). Overseeing in MANET is a test inferable from the dynamic thought of framework topology and resource blocks. A steady arranging structure is proposed for UWB sort out in this paper, focusing on the flimsiness issue got from correspondence foggy zone. This instrument is a cross-layer change of outstandingly doled out on-demand vector (AODV) controlling custom, which is named as $C L S \_A O D V$. The guiding disclosure computation is connected by displaying source coordinating and exceptionally selected on-ask for multipath expels vector coordinating. A preparing model is developed to portray signal characteristics into interface constancy factor and course soundness factor which fills in as a coordinating metric for way decision. Rather than the open path in AODV, the got sign quality can be utilized to uncover the affiliation state data for shady zone want, and for course state viewing. A HELLO-based preemptive neighborhood course fix estimation is familiar with keep the event of affiliation breakage. Welcome message is broadened not only for neighbor perceiving and neighborhood information exchanging, yet moreover as an ON/OFF charge to control the position territory structure and HELLO plan of neighbor centers. The multiplication happens show the movements of CLS_AODV to the degree bundle occurrence degree and run of the mill start to finish yield without trading off the throughput execution separated and AODV.
\end{abstract}

Keywords: Affiliation, Multiplication, Soundness Factor

\section{INTRODUCTION}

Late years have seen a creation imperativeness for ultra wideband (UWB) improvement, which starts from its attracting features, for example, low power utilization, simultaneousness with various progressions in a comparable exchange speed, solid execution under multipath con-ditions, and correct position region affirmation. Using the to an incredible degree low release levels allowed by regulatory workplaces, UWB-based flexible exceptionally named framework (MANET) is pulling in attention as the likelihood for remote individual domain organize (WPAN).

In MANET, centers talk with each other by molding a multihop organizes decentralizedly without the guide of any past establishment. Offhand frameworks need to go up against

Revised Manuscript Received on July 22, 2019.

S.R. Sri Vidhya, Department of Computer Science and Engineering, Bharath Institute of Higher Education and Research, Chennai , India. Email: vidhyasrinivasan1890@gmail.com

C. Geetha, Department of Computer Science and Engineering, Bharath Institute of Higher Education and Research, Chennai, India. Email: gitakannan.2010@gmail.com

Vimala D, Department of Computer Science and Engineering, Bharath Institute of Higher Education and Research, Chennai, India. Email: vimalamuthu3@gmail.com several challenges, for instance, dynamic topology, progressing communication, resource impediment, information transmission organization and bundles convey overhead, in this way making it tangled to setup coordinating traditions. There have been numerous coordinating traditions made for MANET over the span of late years, for example, objective sequenced isolate vector controlling (DSDV), dynamic source coordinating tradition (DSR) and extemporaneous on-ask for vector tradition (AODV) [1]. The on-ask for guiding plans are drawing in an immediate aftereffect of its lesser directing overhead, which begin controlling actions just inside seeing data packs requiring a course.

Unique The inspiration of our work is drawn from the issue of com-munication diminish locale. In such zone, an inside could have a good 'ol fashioned course in its planning table, yet the bundle misfortune degree is elevated and fluctuating. The connection between within point and its next ricochet in correspondence decrease locale is uncertain which will appallingly influence the whole course's stability[19],[21],[23]. The standard clarification behind the occasion of reduce a zone lies in the way that the development for pass on control messages and unicast data packs are astonishing. Arranging control messages may be sent/discovered the chance to exhibit neighbor reachability, while no data packs get through to the going with ricochet[20],[22],[24]. To be express, telecom is reliably done at a basic piece rate while data packs are routinely sent at higher rates. Transmissions at cleave down piece rates are more relifit and can accomplish more cleared than at higher rates. Additionally, pass on message is transmitted with no solicitation, which does not guarantee bidirectional association. The more little pack size of pass on message in like manner gives higher power against square and crash than unicast [3].

AODV relies on sporadic HELLO message for neighbor seeing. It adds to the occasion of correspondence overcast space, which has been underscored in AODV-UU readme record through real testing [5]. Likewise, pass on messages other than experience the naughty impacts of collisions and squares. In our tests, the reenactment take after records demonstrate that HELLO packs are not sent/got in MAC layer every so often. An ordinary wonder saw in take after records exhibits that the HELLO groups kept will be imparted in an impacted later. Thusly impart HELLO message for neighbor accessibility area isn't strong[25],[27],[29].

Each one of the parts indicated above add to the occasion of correspondence foggy zone and course precariousness. Since communication foggy zone aggregates at a specific geographic 
zone, the location information can upgrade coordinating execution through and through. A couple of territory based coordinating traditions have been delivered for exceptionally named frameworks. For example, the avaricious edge stateless thrashing ing (GPSR) is a position-based guiding instrument which has been shown to beat various other coordinating traditions [6]. System is projected to mishandle territory information in course revelation, package hand-off, and course bolster, which makes courses all the more consistent and savage to center point adaptability [7]. Zone reinforced controlling (LAR) limits the quest for another course to a littler 'Solicitation Zone' as per zone data, understanding a gigantic diminishment in vanquishing overhead [8]. Flavor Greedy Routing (HGR) uses the present domain and speed data of the target focus point and neighboring focus focuses to foresee future zones [9]. In the as of now said investigates, coordinating with help from geographic zone data requires each inside point to be equipped with generally speaking masterminding framework (GPS). Anyway there are different conditions where GPS isn't solid, for example indoor conditions [10]. UWB structure is especially reasonable for indoor multipath conditions. Motivation based UWB can interweave right position-an area (in the interest of centimeters) with low-information rate correspondence.

Differentiated satellite-based and GPS-based structure, UWB contraptions enforce land of place without anyone else, which will realize pointless power usage, manage overhead and dealing with delay. If we need to use the UWB radio symbols to transmit client information in two directions, and what's more to situate, a tradeoff must be made against various parts of structure execution.

\section{RESPONSIBILITIES}

The displayed planning fragment takes after a cross-layer game plan way to deal with oversee give low-layer data to execute versatile coordinating structure by perceiving and anticipating the event of correspondence decrease zones, for example precarious affiliations. The low-layer information in this intimates got hail quality, position locale data and data of neighbors, the mix of which can reflect partner state and topological data viably[26],[28],[30].

Our quality based organizing fragment is a cross-layer change of AODV, named as CLS_AODV, including three basic parts: (1) stable course revelation. The unmistakable courses divulgence estimation of AOMDV is stretched out by showing faint zone keep away from once.

An enlisting model is moreover settled to pick the most sta-ble course as opposed to the briefest one, (2) course checking. In the midst of the course bolster process, the likelihood of the occasion of cloudy region is figured in light of the got hail characteristics using an accurate system, and (3) preemptive course repair. There is harm to the discontinuous HELLO plot in AODV. As a difference in HELLO's initial check, HELLO's message is extended not only for neighborhood recognition and information trading, yet in like manner as an ON/OFF solicitation to manage the position district structure and HELLO plan of neighbor focus focuses. The preemptive course fix is locale obliged as opposed to through the whole net-work. The position zone plot is begun to reveal the topokeen information of this area, which, together with the latest and essential complete information of neighbors accumulated by HEL-LO exchanging, ensures a fast and persuading near to course fix. Entertainment occurs show that CLS_AODV gives much best execution over AODV[31],[33],[35].

CLS_AODV: cross-layer reliability based directing part The proposed stable coordinating framework, as a change of AODV, consolidates three essential parts: (1) stable course disclosure, (2) course watching, and (3) preemptive course repair.

\section{STABLE COURSE DISCLOSURE}

In AODV, when a source focus direct needs toward send a bundle to the destination, it from the outset checks its course table to pick in case it has beginning at now a credible course to the target. In the event that it doesn't exist, the source focus point starts a course exposure process by flooding a Route Request bundle through the system. As is resolved in part 2, bestow messages have two or three striking properties that diverse them from information bundles. In spite of whether RREQ messages can be heard, the equivalent may not be considerable for information packs to be ex-changed between two focuses, which adds to temperamental re-refrain joins. We propose an improved stable way accumulation system in light of source planning and AOMDV to find mul-tiple courses between the source and the goal in a solitary course revelation. A soundness based planning metric is likewise appeared for course choice[32],[34],[36].

\section{RESULTS AND DISCUSSIONS}

Much the same as the AOMDV controlling tradition, we insinuate coordinating up-dates procured by methods for RREQs or RREPs as 'course advancements'. A got signal quality farthest point is given the true objective of correspondence murky region area, implied as 'Pre_G-Z_Thresh'. The course promotion groups got underneath the edge should be discarded to evade tricky associations in the midst obviously divulgence. In AOMDV, remembering the ultimate objective to keep up different routes for a comparative sequence number, every center keeps up a variable called plugged bob mean each objective, which addresses the most outrageous hop check of the courses available at the phase of first promotion for a exacting objective plan number [14]. The tradition just allows enduring the reinforcement approaches to run with cut down ricochet check. Regardless of the way that it is critical to guarantee circle opportunity, the course affirmation run unequivocally limits the amount of various courses. With a particular ultimate objective to assemble more genuine courses, course disclosure process is pushed ahead.

In our enlargement, RREQ wrap keeps up the whole route information from source to objective. Source vanquish ing is used just in various courses divulgence. Course table section is the same as AOMDV[37],[39],[41]. Two main policies are used to connect the amount and duration of applicant classes for the vast amount of classes conceivably found.

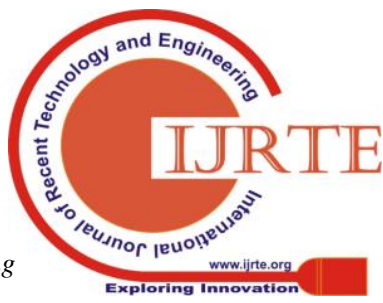


On the other hand, former looks at have exhibited that a directing tradition that gives incredible strength may need to exchange off on throughput gets. Course looking for system will either ends up with most restricted route with long-er (accordingly shaky) associations or stable course with longer course $[15,16]$. In the midst of the course exposure method, foggy region distinguishing proof is completed to begin with, which ensures the yielded associates with be relentless within made out of more associations will likely experience the evil impacts of corruption in course faithful quality. Contemplating this wastefulness, we show a parameter named 'Tolerance_Hop' to keep up a key partition from pointless long ways. The target will perceive a course 'Tolerance_Hop' longer than one officially stopped. RREP tempest can correspondingly be secured since course disclosure all through the entire system is stayed away from.

\section{RREP development}

Improving the RREP signal follows the RREQ signal, including the affirmation of Forward LSF list and the foggy district. Before issuing the RREP separately, each inside point should bring the LSF estimate of its upper connection into Forward LSF list. An additional one-off is appended to the RREP set called Reverse LSF list, a copy of Reverse LSF list in the RREQ message associative at the goal.

\section{CONCLUSION}

A reliability-based scheduling chapter is suggested in this document to tackle the problem of overcast region correspondence, which is AODV's cross-layer update. The quality of the received sign is used as a portion of CLS AODV to uncover the state of membership information as much as it might reasonably be normal. Regardless of the way that IR-UWB advancement has the breaking point of a right area, the position zone plot is begun in a re-stricted zone just if amazingly indispensable with a specific end goal to smother its imperativeness usage and control overhead.

The methodologies of course exposure for AOMDV and source coordination are joined and enhanced with the ultimate goal of collecting different methods. A figuring model is set up to make coordinating estimations for way assurance with respect to course reliability, which has been ace ven practical by the diversion comes to fruition. Instead of AODV's responsive technique, CLS AODV can proactively react to related breakage by schemes for viewing the state of the course and wanting foggy area[38],[40]. HELLO signal is reached in the preemptive course fix plot to have a much more important effect than previously. The cream of HELLO design and zone helped coordinating system ensures a snappy and effective course entertainment technique. Reenactment works out as intended show that CLS_AODV can diminish the bundle misfortune degree and normal start to finish concede of UWB MANET fundamentally without trading off the throughput execution. From this time forward, the zone position strategy should be initiated just if amazingly essential. Other than geographic zones, remote signs have properties that view other information as contemplated the correspondence states between center points. At the end of the day, if the characteristics of a distant flag can be retrieved, the information should be aerated and cooled past the data being the near future. Nevertheless, in compact frameworks, routes

transferred, which has been ended up being to be efficient by past examinations [11-13]. As there is no power manage in our model show, got hail quality is utilized to check and suspect associate soundness as opposed to region information in a couple of conditions.

\section{REFERENCES}

[1] Kumaravel A., Rangarajan K.,Algorithm for automaton specification for exploring dynamic labyrinths,Indian Journal of Science and Technology,V-6,I-SUPPL5,PP-4554-4559,Y-2013

[2] P. Kavitha, S. Prabakaran "A Novel Hybrid Segmentation Method with Particle Swarm Optimization and Fuzzy C-Mean Based On Partitioning the Image for Detecting Lung Cancer" International Journal of Engineering and Advanced Technology (IJEAT) ISSN 2249-8958, Volume-8 Issue-5, June 2019

[3] Kumaravel A., Meetei O.N.,An application of non-uniform cellular automata for efficient cryptography,2013 IEEE Conference on Information and Communication Technologies, ICT 2013,V-,I-,PP-1200-1205,Y-2013

[4] Kumarave A., Rangarajan K.,Routing alogrithm over semi-regular tessellations,2013 IEEE Conference on Information and Communication Technologies, ICT 2013,V-,I-,PP-1180-1184,Y-2013

[5] P. Kavitha, S. Prabakaran "Designing a Feature Vector for Statistical Texture Analysis of Brain Tumor" International Journal of Engineering and Advanced Technology (IJEAT) ISSN: 2249-8958, Volume-8 Issue-5, June 2019

[6] Dutta P., Kumaravel A.,A novel approach to trust based identification of leaders in social networks, Indian Journal of Science and Technology,V-9,I-10,PP--,Y-2016

[7] Kumaravel A., Dutta P.,Application of Pca for context selection for collaborative filtering,Middle - East Journal of Scientific Research,V-20,I-1,PP-88-93,Y-2014

[8] Kumaravel A., Rangarajan K.,Constructing an automaton for exploring dynamic labyrinths,2012 International Conference on Radar, Communication and Computing, ICRCC 2012,V-,I-,PP-161-165,Y-2012

[9] P.Kavitha, S. Prabakaran "Adaptive Bilateral Filter for Multi-Resolution in Brain Tumor Recognition" International Journal of Innovative Technology and Exploring Engineering (IJITEE) ISSN: 2278-3075, Volume-8 Issue-8 June, 2019

[10] Kumaravel A.,Comparison of two multi-classification approaches for detecting network attacks, World Applied Sciences Journal,V-27,I-11,PP-1461-1465,Y-2013

[11] Tariq J., Kumaravel A.,Construction of cellular automata over hexagonal and triangular tessellations for path planning of multi-robots,2016 IEEE International Conference on Computational Intelligence and Computing Research, ICCIC 2016,V-,I-,PP--,Y-2017

[12] Sudha M., Kumaravel A.,Analysis and measurement of wave guides using poisson method,Indonesian Journal of Electrical Engineering and Computer Science,V-8,I-2,PP-546-548,Y-2017

[13] Ayyappan G., Nalini C., Kumaravel A.,Various approaches of knowledge transfer in academic social network, International Journal of Engineering and Technology,V-,I-,PP-2791-2794,Y-2017

[14] Kaliyamurthie, K.P., Sivaraman, K., Ramesh, S. Imposing patient data privacy in wireless medical sensor networks through homomorphic cryptosystems 2016, Journal of Chemical and Pharmaceutical Sciences92.

[15] Kaliyamurthie, K.P., Balasubramanian, P.C.An approach to multi secure to historical malformed documents using integer ripple transfiguration 2016 Journal of Chemical and Pharmaceutical Sciences92.

[16] A.Sangeetha,C.Nalini,"Semantic Ranking based on keywords extractions in the web", International Journal of Engineering \& Technology, 7 (2.6) (2018) 290-292

[17] S.V.GayathiriDevi,C.Nalini,N.Kumar,"An efficient software verification using multi-layered software verification tool "International Journal of Engineering \& Technology, 7(2.21)2018 454-457

[18]C.Nalini,ShwtambariKharabe,"A Comparative Study On Different Techniques Used For Finger - Vein Authentication", International Journal Of Pure And Applied Mathematics, Volume 116 No. 8 2017, 327-333, Issn: 1314-3395 
[19] M.S. Vivekanandan and Dr. C. Rajabhushanam, "Enabling Privacy Protection and Content Assurance in Geo-Social Networks", International Journal of Innovative Research in Management, Engineering and Technology, Vol 3, Issue 4, pp. 49-55, April 2018.

[20] Dr. C. Rajabhushanam, V. Karthik, and G. Vivek, "Elasticity in Cloud Computing", International Journal of Innovative Research in Management, Engineering and Technology, Vol 3, Issue 4, pp. 104-111, April 2018.

[21] K. Rangaswamy and Dr. C. Rajabhushanamc, "CCN-Based Congestion Control Mechanism In Dynamic Networks", International Journal of Innovative Research in Management, Engineering and Technology, Vol 3, Issue 4, pp. 117-119, April 2018.

[22] Kavitha, R., Nedunchelian, R., "Domain-specific Search engine optimization using healthcare ontology and a neural network backpropagation approach", 2017, Research Journal of Biotechnology, Special Issue 2:157-166

[23] Kavitha, G., Kavitha, R., "An analysis to improve throughput of high-power hubs in mobile ad hoc network", 2016, Journal of Chemical and Pharmaceutical Sciences, Vol-9, Issue-2: 361-363

[24] Kavitha, G., Kavitha, R., "Dipping interference to supplement throughput in MANET" , 2016, Journal of Chemical and Pharmaceutical Sciences, Vol-9, Issue-2: 357-360

[25] Michael, G., Chandrasekar, A.,"Leader election based malicious detection and response system in MANET using mechanism design approach", Journal of Chemical and Pharmaceutical Sciences(JCPS) Volume 9 Issue 2, April - June 2016

[26] Michael, G., Chandrasekar, A.,"Modeling of detection of camouflaging worm using epidemic dynamic model and power spectral density", Journal of Chemical and Pharmaceutical Sciences(JCPS) Volume 9 Issue 2, April - June 2016.

[27] Pothumani, S., Sriram, M., Sridhar, J., Arul Selvan, G., Secure mobile agents communication on intranet,Journal of Chemical and Pharmaceutical Sciences, volume 9, Issue 3, Pg No S32-S35, 2016

[28] Pothumani, S., Sriram, M., Sridhar, Various schemes for database encryption-a survey, Journal of Chemical and Pharmaceutical Sciences, volume 9, Issue 3, Pg NoS103-S106, 2016

[29] Pothumani, S., Sriram, M., Sridhar, A novel economic framework for cloud and grid computing, Journal of Chemical and Pharmaceutical Sciences, volume 9, Issue 3, Pg No S29-S31, 2016

[30] Priya, N., Sridhar, J., Sriram, M. "Ecommerce Transaction Security Challenges and Prevention Methods- New Approach” 2016 ,Journal of Chemical and Pharmaceutical Sciences, JCPS Volume 9 Issue 3.page no:S66-S68

[31] Priya, N.,Sridhar,J.,Sriram, M."Vehicular cloud computing security issues and solutions" Journal of Chemical and Pharmaceutical Sciences(JCPS) Volume 9 Issue 2, April - June 2016

[32] Priya, N., Sridhar, J., Sriram, M. "Mobile large data storage security in cloud computing environment-a new approach" JCPS Volume 9 Issue 2. April - June 2016

[33] Anuradha.C, Khanna.V, "Improving network performance and security in WSN using decentralized hypothesis testing "Journal of Chemical and Pharmaceutical Sciences(JCPS) Volume 9 Issue 2, April - June 2016

[34] Anuradha.C, Khanna.V, "A novel gsm based control for e-devices" Journal of Chemical and Pharmaceutical Sciences(JCPS) Volume 9 Issue 2, April - June 2016

[35] Anuradha.C, Khanna.V, "Secured privacy preserving sharing and data integration in mobile web environments " Journal of Chemical and Pharmaceutical Sciences(JCPS) Volume 9 Issue 2, April - June 2016.

[36] Sundarraj, B., Kaliyamurthie, K.P. Social network analysis for decisive the ultimate classification from the ensemble to boost accuracy rates 2016 International Journal of Pharmacy and Technology

[37] Sundarraj, B., Kaliyamurthie, K.P. A content-based spam filtering approach victimisation artificial neural networks 2016 International Journal of Pharmacy and Technology83.

[38] Sundarraj, B., Kaliyamurthie, K.P. Remote sensing imaging for satellite image segmentation 2016 International Journal of Pharmacy and Technology 83.

[39] Sivaraman, K., Senthil, M. Intuitive driver proxy control using artificial intelligence 2016 International Journal of Pharmacy and Technology 84 .

[40] Sivaraman, K., Kaliyamurthie, K.P. Cloud computing in mobile technology 2016 Journal of Chemical and Pharmaceutical Sciences 92.

[41] Sivaraman, K., Khanna, V. Implementation of an extension for browser to detect vulnerable elements on web pages and avoid click jacking 2016 Journal of Chemical and Pharmaceutical Sciences92.

\section{AUTHORS PROFILE}

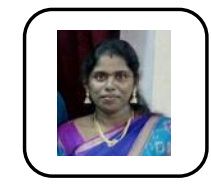

S.R. Sri Vidhya, Assistant Professor, Department of Computer Science \& Engineering, Bharath Institute of Higher Education and Research, Chennai, India

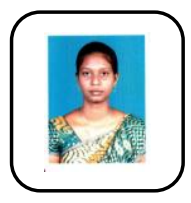

C. Geetha, Assistant Professor, Department of Computer Science \& Engineering, Bharath Institute of Higher Education and Research, Chennai, India

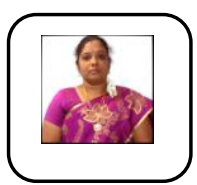

Vimala D Assistant Professor, Department of Computer Science \& Engineering, Bharath Institute of Higher Education and Research, Chennai, India 